\title{
Presence of a single nucleotide polymorphism (RS3758581) in a boy with DRESS syndrome
}

\author{
HULYA ANIL ${ }^{l}$, KORAY HARMANCI ${ }^{1}$, RAHMI T. TEKIN ${ }^{2}$, ABDULKADIR KOCAK
}

${ }^{1}$ Department of Pediatric Allergy and Immunology, Eskisehir Osmangazi University Hospital, Meşelik, Turkey

${ }^{2}$ Department of Pediatrics, Eskisehir Osmangazi University Hospital, Meşelik, Turkey

\begin{abstract}
Drug rash with eosinophilia and systemic symptoms (DRESS) syndrome is a rare, potentially life-threatening, drug-induced hypersensitivity reaction that includes rash, hematologic abnormalities, lymphadenopathy, and internal organ involvement. The pathogenesis of DRESS syndrome is partially understood. Various medications have been described as the cause of DRESS syndrome. Phenytoin and allopurinol are the most commonly reported culprit drugs, although more than 50 drugs can induce DRESS syndrome. Members of the cytochrome P450 (CYP) superfamily are the most commonly involved enzymes in metabolism of drugs such as phenytoin. This case report addresses the influence of CYP2C9 genetic polymorphism (a single nucleotide polymorphism) on phenytoin drug metabolism, thereby causing DRESS syndrome.
\end{abstract}

Key words: DRESS syndrome, phenytoin, CYP2C9 gene polymorphisms.

(Centr Eur J Immunol 2017; 42 (4): 409-411)

\section{Introduction}

Drug rash with eosinophilia and systemic symptoms (DRESS) syndrome is a rare, potentially life-threatening, drug-induced hypersensitivity reaction that includes rash, hematologic abnormalities, lymphadenopathy, and internal organ involvement $[1,2]$. The pathogenesis of DRESS syndrome is partially understood. Various medications have been described as the cause of DRESS syndrome. Phenytoin and allopurinol are the most commonly reported culprit drugs, although more than 50 drugs can induce DRESS syndrome [3-6]. Members of the cytochrome P450 (CYP) superfamily are the most commonly involved enzymes in metabolism of drugs such as phenytoin. Genetic variation in the CYP2C9 gene can affect metabolism of phenytoin leading to altered phenotypes. Individuals with CYP2C9 gene polymorphisms were found to have an increased risk of severe cutaneous adverse reactions such as DRESS syndrome compared with the normal population [7, 8]. This case report addresses the influence of CYP2C9 genetic polymorphism (a single nucleotide polymorphism) on phenytoin drug metabolism, thereby causing DRESS syndrome.

\section{Case description}

A 6-year-old boy presented to the clinic with complaints of fever and rash lasting for about a week. He had no specific medical history before phenytoin was prescribed upon the suspicion of epilepsy. Three weeks later, he started to complain of fever (highest $38.8^{\circ} \mathrm{C}$ ) and rash involving the trunk and extremities. Five days after the onset of symptoms, he presented to our clinic with these symptoms. On examination, maculopapular eruptions consisting of erythematous lesions varying from pin point in size up to a few millimeters across, through a wider range of rashes, were seen predominantly on the trunk and extremities. The skin rash tended to be confluent and was widespread on the body. He had submandibular and cervical lymphadenopathies about $2 \times 2 \mathrm{~cm}$ confirmed by ultrasonography. His vital signs upon admission to the service were $90 / 60 \mathrm{mmHg}$ for blood pressure, $80 / \mathrm{min}$ for pulse rate, $28 / \mathrm{min}$ for respiratory rate and $38.8^{\circ} \mathrm{C}$ for body temperature.

Figure 1 shows generalized erythematous maculopapular rash in the patient's abdomen and leg.

Laboratory findings showed leucocytosis (white blood

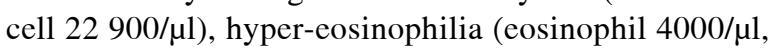
17.4\%), hepatitis (AST 1492 IU/1 [10-40 IU/1], ALT 702 IU/1 [10-40 IU/1]), hyperbilirubinemia (total bilirubin $5.08 \mathrm{mg} / \mathrm{dl}[0.3-1.3 \mathrm{mg} / \mathrm{dl}]$, and direct bilirubin $4.23 \mathrm{mg} /$ dl [0.05-0.40 mg/dl]).

\section{Diagnosis}

Work-up for eosinophilia showed normal levels of serum IgE and complement. Stool studies failed to show any evidence of parasites. Blood and urine cultures were all negative. Furthermore, serological studies for rheumatoid

Correspondence: Hulya Anil, Department of Pediatric Allergy and Immunology, Eskisehir Osmangazi University Hospital, Meşelik, 26040 Eskisehir, Turkey, tel. +90-222-2397929, e-mail: hulyaanil26@gmail.com Submitted: 26.05.2016; Accepted: 16.11.2016 

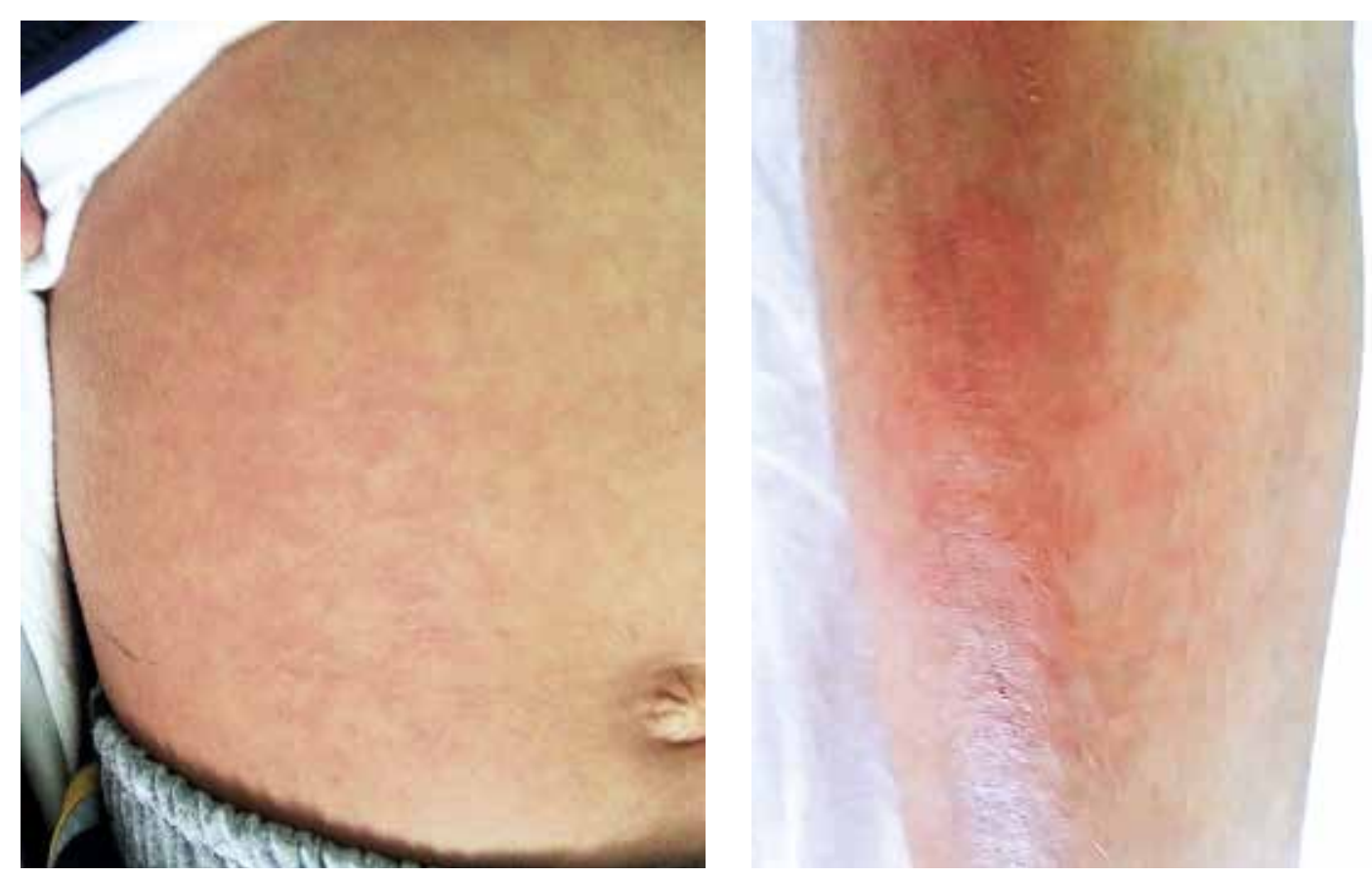

Fig. 1. Generalized erythematous maculopapular rash in the patient's abdomen and leg

factor, ANA and anti-DNA were also negative. According to serum tests, all herpes simplex virus, cytomegalovirus, Epstein-Barr virus, human immunodeficiency virus (HIV), and hepatitis $\mathrm{A}, \mathrm{B}$, and $\mathrm{C}$ viruses, were negative too. Biopsy of the skin lesions showed mild spongiotic epidermis and a mild dermal chronic inflammatory cell infiltrate composed of lymphocytes, histiocytes and occasional eosinophils with focal exocytosis of lymphocytes into the epidermis and associated vacuolar damage to the basal layer. These findings were consistent with the histological description typically found in this syndrome; however, it was not pathognomonic.

The laboratory and clinical findings, coupled with associated fever, generalized rash, eosinophilia, hepatic dysfunction, and lymphadenomegaly, led to the diagnosis of DRESS syndrome. Phenytoin was stopped when he was admitted to the hospital and prednisolone was started on the fifth day of hospitalization. The clinical course was favorable, with progressive regression of symptoms after steroid initiation. We planned a pharmacogenetic study for CYP2C9 gene polymorphisms two months after the steroid therapy.

\section{Discussion}

"Drug rash with eosinophilia and systemic symptoms" was first introduced in 1996 by Bocquet, to describe patients exhibiting a drug-induced condition characterized by an extensive rash, fever, lymphadenopathy, hematologic abnormalities, hepatitis, and involvement of the kidneys, lungs, heart, or pancreas [1]. The initial symptoms in the present case were fever and skin eruption three weeks after being exposed to the drug. Cutaneous lesions can range from erythematous papules to plaques, pustules, and eczematous lesions [8]. The laboratory abnormalities in our case included elevated white blood cell count with increased eosinophils, hepatitis, and direct hyperbilirubinemia. RegiSCAR proposes a series of criteria for DRESS, according to which hospitalized patients with drug rash must have at least 3 of 4 systemic features (fever, lymphadenopathy, internal organ involvement, hematological abnormalities) [10]. In the present report, our patient developed all 4 criteria of the DRESS syndrome, and the Kardaun score was 7 [11].

Phenytoin is a first-line antiepileptic drug but can cause adverse reactions from maculopapular exanthema to life-threatening reactions. It is estimated that about $19 \%$ of patients taking phenytoin develop hypersensitivity reactions [8]. Not all patients taking phenytoin develop phenytoin-induced severe cutaneous adverse reactions such as DRESS, Steven-Johnson syndrome and toxic epidermal necrolysis [12]. Evidence suggests that genetic factors also might have a significant role in the pathogenesis of phenytoin-induced severe cutaneous adverse reactions [8, 12-16].

Phenytoin is metabolized primarily by the cytochrome P450 (CYP) enzyme. CYP2C9, a member of the cytochrome-P450 enzyme superfamily, is a monooxygenase that metabolizes drugs such as phenytoin [18]. Genetic variation in the $C Y P 2 C 9$ gene can affect the metabolism, leading to altered phenotypes. It was discovered that $C Y P 2 C 9$ gene 
polymorphisms known to cause a $93 \%$ to $95 \%$ reduction in phenytoin clearance are important genetic factors for phenytoin-related severe cutaneous adverse reactions [8, 12-16]. To investigate the genetic factors associated with phenytoin-related DRESS syndrome, we carried out a genome-wide association study, followed by direct sequencing of the associated gene and replication analyses.

Here we report a case of DRESS secondary to phenytoin, in which an underlying genetic predisposition (a single nucleotide polymorphism) was found. Genetic analysis showed a missense mutation in CYP2C9 exon 7 called rs3758581. Single nucleotide polymorphisms on the $C Y P 2 C 9$ gene which can cause amino acid changes, such as rs3758581 (Ile331Val), affect CYP2C9 enzyme activity and its substrate specificity; thus rs 3758581 is significantly associated with severe cutaneous adverse phenytoin reactions (e.g. Steven Johnson, DRESS syndrome) [8].

\section{Conclusions}

DRESS syndrome is a possible complication of phenytoin treatment that clinicians should keep in mind. We recommend that, wherever possible, clinicians should carry out CYP2C9 genotyping of epileptic patients before prescribing phenytoin, with progress in molecular technology. Thus identification of patients' genotype prior to phenytoin administration could potentially prevent life-threatening reactions such as DRESS syndrome.

The authors declare no conflict of interest.

\section{References}

1. Bocquet H, Bagot M, Roujeau JC (1996): Drug-induced pseudolymphoma and drug hypersensitivity syndrome (drug rash with eosinophilia and systemic symptoms): DRESS. Semin Cutan Med Surg 15: 250-257.

2. Cacoub P, Musette P, Descamps V, et al. (2011): The DRESS syndrome: A literature review. Am J Med 124: 588-597.

3. Chen YC, Chiu HC, Chu CY (2010): Drug reaction with eosinophilia and systemic symptoms: a retrospective study of 60 cases. Arch Dermatol 146: 1373-1379.

4. Um SJ, Lee SK, Kim YH, et al. (2010): Clinical features of drug induced hypersensitivity syndrome in 38 patients. J Invest Allergol Clin Immunol 20: 556-562.

5. Wongkitisophon $\mathrm{P}$, Chanprapaph K, Rattanakaemakorn $\mathrm{P}$, et al. (2012): Six year retrospective review of drug reaction with eosinophilia and systemic symptoms. Acta Derm Venereol 92: 200-205.

6. Ding WY, Lee CK, Choon SE (2010): Cutaneous adverse drug reactions seen in a tertiary hospital in Johor, Malaysia. Int J Dermatol 49: 834-841.

7. Chung WH, Chang WC, Lee YS, et al. (2014): Genetic variants associated with phenytoin-related severe cutaneous adverse reactions. JAMA 312: 525-534.

8. Chung WH, Hung SI (2012): Risk assessment for phenytoIn-Induced adverse drug reactions United States. Patent num- ber.0329045 A1: United States Patent Application Publication.

9. Kocaoglu C, Cilasun C, Solak ES, et al. (2013): Successful treatment of antiepileptic drug-induced DRESS syndrome with pulse methylprednisolone. Case Rep Pediatr 2013: 928910.

10. Cacoub P, Musette P, Descamps V, et al. (2011): The DRESS syndrome: a literatüre review. Am J Med 124: 588-597.

11. Kardaun SH, Sidoroff A, Valeyrie-Allanore L, et al. (2013): Variability in the clinical pattern of cutaneous side-effects of drugs with systemic symptoms: does a DRESS syndrome really exist? Br J Dermatol 169: 1071-1080.

12. Babu SP, Ramesh V, Samidorai A, et al. (2013): Cytochrome P450 2C9 gene polymorphism in phenytoin induced gingival enlargement: A case report. J Pharm Bioallied Sci 5: 237-239.

13. Tassaneeyakul W, Prabmeechai N, Sukasem C, et al. (2016): Associations between HLA class I and cytochrome P450 2C9 genetic polymorphisms and phenytoin-related severe cutaneous adverse reactions in a Thai population. Pharmacogenet Genomics 26: 225-234.

14. Takanashi K, Tainaka H, Kobayashi K, et al. (2000): CYP2C9 Ile359 and Leu359 variants: enzyme kinetic study with seven substrates. Pharmacogenetics 10: 95-104.

15. Kesavan R, Narayan SK, Adithan C (2010): Influence of CYP2C9 and CYP2C19 genetic polymorphisms on phenytoininduced neurological toxicity in Indian epileptic patients. Eur J Clin Pharmacol 66: 689-696.

16. Depondt C, Godard P, Espel RS, et al. (2011): A candidate gene study of antiepileptic drug tolerability and efficacy identifies an association of CYP2C9 variants with phenytoin toxicity. Eur J Neurol 18: 1159-1164.

17. Niinuma Y, Saito T, Takahashi M, et al. (2014): Functional characterization of 32 CYP2C9 allelic variants. Pharmacogenomics J 14: 107-114.

18. Twardowschy CA, Werneck LC, Scola RH, et al. (2011): CYP2C9 polymorphism in patients with epilepsy: genotypic frequency analyzes and phenytoin adverse reactions correlation. Arq Neuropsiquiatr 69: 153-158. 